REGULAR ARTICLE

\title{
COATING OF GUAVA (PSIDIUM GUAJAVA L.) FRUITS WITH BOTANICAL EDIBLE OILS FOR SHELF LIFE AND FRUIT FLIES
}

\author{
ESAMELDIN B. M. KABBASHI ${ }^{*}$, NAWAL A. ABDELRAHMAN ${ }^{\prime}$, MOHAMED MODATHIR ${ }^{2}$, \\ AWAD S. A. SIYAM3
}

\author{
${ }^{1}$ The National Food Research Center, Federal Ministry of Agriculture and Forestry, Khartoum, Sudan \\ ${ }^{2}$ Soba Research Station, Agricultural Research Corporation, Federal Ministry of Agriculture and Forestry, Khartoum, Sudan
}

3Fatoum Factory, South Khartoum, Sudan

\begin{abstract}
Guava (Psidium guajava L.) fruit is a popular nutritious dessert in Sudan. It is famous for its medicinal values as a prompt cure for digestive disorders and respiratory ailness this besides being a rich source of $\mathrm{C}$ vitamin. This fruit is highly amenable to fruit fly attack and it is a harbor of eggs of five different species [Ceratitis capitata Wied.; Ceratitis quinaria Bez.; Ceratitis cosyra Wlk.; Bactrocera invadens De Trusta and White and Bactrocera zonata (Saunders)] in Sudan. This is stimulating to a chain of endless research to combat these notorious pests which account for huge losses in this crop that reach up to $80 \%$ or even more. This research aimed at evaluating the effect of oil coating on fruit fly infestation and the quality indexes in guava fruit using five different botanical edible oils. The results showed that groundnut (Arachis hypogaea L.) (GNO), sesame (Sesamum indicum L.) (SO), baobab (Adansonia digitata L.) (BO), olive (Olea europaea L.) (OO) and neem (Azadirachta indica A. Juss) (NO) oils effected a corrected disinfestation of 80, 72, 56, 52 and 28\% in test fruits brought from Kadaro orchards North Khartoum, respectively. The corresponding average readings of maggots in infested fruits were 4, 17, 11, 5, 7 and [10 (for the first 4) and 26 for NO] in the control. Two essential quality indexes were checked in test fruits which included fruit color (FC) and firmness (FF). The corrected test readings reflected $64,80,44,52,-4$ and [8 (for the first 4) and 20 for NO] in the control sustained FC for GNO, SO, BO, OO, NO and the control, respectively. However, the corresponding readings for FF were 3 (medium) for all oils and 4 (soft) for the controls. These results reflect a potent and the best efficacy of peanut and sesame oils, of the five test oils, in controlling fruit flies in guava and extending its shelf life.
\end{abstract}

Keywords: Guava, Fruit flies, Botanical edible oils, Coating, Shelf life and disinfestation

\section{INTRODUCTION}

The family Myrtaceae include more than 300 genera to which the genus Psidium belongs. This genus by itself include about 150 species the best of which known is guajava. This fruit is a tropical and subtropical fruit [1]. Guava (P. guajava) is one the most popular desserts in the world. That is, its nutritional values and tasty characteristics qualify it for that [2]. Guava fruit is a magnificent food due to its nutritional contents which include vitamin B complex, and minerals like iron, potassium, calcium and dietary fibres. These besides being one of the richest sources of vitamin C (ascorbic acid) ever known in the world. That is, it is considered next to acerola (Malpighia glabra L.). Guava ( $P$. guajava) is considered a high-rate moisture loss fruit together with mango, papaya, litchi, rambutan and pineapple [3]. However, fruit flies in Sudan cause a huge economic loss in a number of important fruit crops such as guava, mango and grape fruit. That is, in a study in South Kordofan State these insects reflected an economic loss up to $67 \%$ in guava [4]. Three species were reported to infest guava fruits in Sennar, North Kordofan and Nile States. These were Ceratitis cosyra Wlk, C. capitata Weid. and Bactrocera dorsalis (Hendel) [5]. Nevertheless, the fruit and vegetable coating with edible materials is a known practice since the 1930s. That is, edible coating is a safe and friendly practice to human and his environment as well. Coating with oils offer fruits protection from bruising by being slippery, shininess and retard maturation [6]. That is, it preserves the quality of fruits and vegetables. In addition, it adds to the fruit nutritional and market values [7]. Edible coating also considered to play as antimicrobial barriers and some coating materials have antimicrobial activities too [8]. The soft skin of guava renders it amenable to perish, accordingly some postharvest treatments such as oil coating were practiced to combat that loss. However, in a study it was found that $1 \%$ hydroxypropyl methyl cellulose and $0.3 \%$ of palm oil edible coating of guava fruits

\section{Received o6 January 2018; Accepted 28 April 2018 \\ *Corresponding Author}

Esameldin B. M. Kabbashi

The National Food Research Center, Federal Ministry of Agriculture and Forestry, Khartoum, Sudan

Email: esameldinkabbashi@gmail.com

( $T$ This article is open access and licensed under the terms of the Creative Commons Attribution License (http://creativecommons.org/licenses/by/4.o/) which permits unrestricted, use, distribution and reproduction in any medium, or format for any purpose, even commercially provided the work is properly cited. Attribution - You must give appropriate credit, provide a link to the license, and indicate if changes were made. 
resulted in a significant delay to ripening, conserved fruit characteristics and extended its shelf life up to $12 \mathrm{~d}$ at $24 \pm 1^{\circ} \mathrm{C}$ and $65 \pm 5 \% \mathrm{RH}$ [9]. In addition, a mixture of candelilla wax with white mineral oil and mesquite gum was used as an edible coating for guava [10].

The results, of this mixtures treatment, reflected a retarded shelf life of six days due to a reduction in ethylene production by $80 \%$ and the weight loss by $30 \%$ as compared to the untreated control [10] (Tomas et al., 2005). Palm oil (20\%) coating of guava fruit was reported the best among other used coatings [starch, liquid paraffin, fatty acid sugar esters and low density polyethylene (LDPE)]. That is, palm oil coats had the edge by being the top in maintaining quality and fresh guava stored for two months at $10^{\circ} \mathrm{C}$ [11]. However, coating with mineral oils alone has been performed in a number of tropical fruits such as guava, mango, avocado pineapple, papaya and banana. The obtained results of shelf life extension varied with the treated crop [6]. This experiment studied the effect of oil coating of five plant oils (groundnut, sesame, baobab, olive and neem oils) on quality of guava fruit.

\section{MATERIALS AND METHODS}

\section{Materials}

The following stuffs were used in this experiment

1. Freshly harvested guava fruits from orchards in Kadaro (30 Km North Khartoum Center). The selected test fruits were of yellowish green in color and of medium FF.

2. The BO was provided by Fatoum Factory in South Khartoum. The OO was from a Lebanese mill in Beirut. The GNO was brought from Farouque Oil Mill, Khartoum North Industrial Area. The SO was from Elnasr Oil Mill Company, Khartoum North. The NO was taken from Soba Research Station (SRS) of the Agricultural Research Corporation (ARC), Khartoum South.

3. Storage cartoons were supplied by Oodellayl Export and Imports Company, Khartoum North.

4. Cotton wick for the dressing of fruits was supplied from Kabota Medical Company, Khartoum 3.

5. The laboratory facilities of the Canning Department, The National Food Research Center were exploited in the experimentation.

\section{Methods}

Test fruits were washed thoroughly with tap water in a big aluminum basin. These fruits were dried under a ceiling fan for $10 \mathrm{~min}$. Each fruit was dressed with the test oils, separately, and then put in cartoon boxes and left on bench for four days under $18 \% \mathrm{RH}$ and $30{ }^{\circ} \mathrm{C}$.

Dissection was done after the set storage period. Readings were then taken regarding infestation, number of maggots per fruit, FF and FC. Each test had 25 replicates as well as a corresponding control. The test fruits used were of medium size (4 X $5 \mathrm{~cm}^{2}$ ) and medium color (yellowish green) [12].

The analysis of the obtained data was by analysis of variance (ANOVA) using the mode, mean, range and percentage. However, the insect infestation parameters entomological results were calculated by getting rid of the effect of control (correction) using the standard equation [13]

\section{RESULTS AND DISCUSSION}

Oil coating of guava fruits on fruit fly infestation are given in table 1 . The test disinfestation results of GNO, SO, BO, OO and NO were 96, 88, 72, 68 and 40 in order. The records of the corrected disinfestation were 8o, 72, 56, 52 and 28 , respectively. These findings reflected the potency of these edible coating materials in disinfesting guava fruits from fruit flies as compared to the control with natural non-incidence of infestation valuated as 16 (for the first 4 oils) and 12 (for NO) in untreated lots. The average number of worms/infested fruit was higher in the control as compared to the treated lots (generally speaking, table 1). That is, 4, 17, 11, 5 and 7 worms/infested fruit compared to 10 and 26 in the corresponding controls. However, the percentage, of the difference between the treated and untreated fruits with respect to worms/infested fruits, reached up to $271 \%$ which count to approximately three folds. The infestation percentage of the test oil coated fruits, in order, was 4, 12, 28, 32 and 60 compared to 84 and $88 \%$ for the untreated control (table 1). All the above mentioned results showed that all the test oils had a degree of control over fruit flies in guava through coating. However, GNO was the best followed by SO whereas BO and OO gave good control too. However, NO reflected the least control of fruit flies in test fruits. These results of NO were unexpected since neem is much known of its insecticidal activity in tests done through decades. That is, neem products were reported to have about 24 known products of insecticidal activity.

The effect of coating of guava fruits with the five test oils (GNO, SO, BO, OO and NO) reflected corrected sustainability of FC of $64,80,44,52$ and-4. Nevertheless, SO was the best in preservation of $\mathrm{FC}(80 \%)$ followed by GNO (64\%), OO (52), and BO (44\%), respectively, whereas, NO obtained the least $(-4 \%)$ and poorest result that even less than the control in the FC parameter (table 2). The corrected results of sustained $\mathrm{FF}$ were $48 \%$ (for each of GNO, BO and $\mathrm{NO}$ ), 40\% (SO), and 72\% (OO), respectively (table 2). However, the average $\mathrm{FF}$ was 3 (medium) for all the treated fruits and 4 (soft) for all the corresponding controls. These results showed that all the test oil coatings performed well in preserving the treated guava fruit quality. That is, all the test oils, except NO, can be used as edible coating elements for preserving quality guava fruits and controlling fruit flies with varying efficacy. The components of the test oils are summarized in table 3 . That is, with respect to the GNO and SO which showed the best results. The former performed the first in insect control and in the overall quality sustainability followed by SO and OO. GNO contains a total of $81 \%$ unsaturated fatty acids (48\% monounsaturated as oleic acid and 33\% polyunsaturated as linoleic acid) (table 3). The corresponding results for SO were $81.4 \%$ (39\% oleic acid and $41 \%$ linoleic acid besides 0.7 for each of $\omega-7$ and $\omega-3$ ) (table 3). The GNO showed higher results in the saturated fatty acids $19 \%$ ( $17 \%$, palmitic and $2 \%$ for stearic acid) whereas the corresponding results for SO were $8 \%$ and $5 \%$, respectively (table 3). These results may justify the similarity in their performance in this test compared to other test oils. These results may be supported by the results reported earlier that said GNO is analogous to SO [14]. However, GNO and SO reflected the highest records in viscosity (0.0574 and $0.0562 \mathrm{~Pa}^{-\mathrm{S}^{-1}}$ at $26^{\circ} \mathrm{C}$, respectively) and the corresponding results at $38^{\circ} \mathrm{C}$ were (o.0380 and $0.0351 \mathrm{~Pa}^{-1} \mathrm{~S}^{-1}$ ) (table 4). However, the viscosity of all the other test oils is less than the above mentioned except NO (table 3). However, the viscosity 
increases proportionally with the unsaturation of fat (fats are more viscous than oils). In this test GNO, SO and OO have the highest records of viscosity and unsaturated fatty acids index. However, the records appear in tables 3 and 4 reflected a direct proportionality between the degree of unsaturation and the viscosity. $\mathrm{BO}$ was reported to have a medium viscosity [15]. However, OO is less viscous than GNO and SO due to the higher content of monounsaturated fatty acids $75 \%$ Oleic acid (Table, 3 ). These results may account for the differentiation in the results obtained by the coating of these three oils. In addition, BO rank after the above three mentioned oils in viscosity and unsaturated fatty acids (Tables 3 and 4) and also this gives a clear justification for its performance in the quality test of guava fruit coating (Tables 1 and 2). The better performance of $\mathrm{BO}$ compared to $\mathrm{OO}$ in fruit disinfestation may be attributed to the cycloprpene fatty acid (Malvanic acid) which is known of negative impacts to living organisms including man [16]. However, NO inspite of its known insecticidal activity but it showed the least performance in this test. This may be attributed to the highest average content of saturated fatty acids (40\%) compared to the other test oils (table 3). However, the reported viscosity of NO (table 4) is relatively higher compared to its average components of fatty acids. That is, the NO viscosity was found 0.0835 and $0.0455 \mathrm{~Pa}^{-\mathrm{S}^{-1} \text { at }}$ $30^{\circ} \mathrm{C}$ and $40^{\circ} \mathrm{C}$, respectively (Table, 4) this may be attributed to nature of the extraction and impurities of proteins and other components, perhaps. The worst performance of $\mathrm{NO}$ with respect to fruit quality in this experiment may reflect the vitality of smothering the fruits from gas exchange by the oil smear and the degree of overtight coverage determined the preserved fruit quality and brown spots. However, a comprehensive research is needed including the chemical, physical and other characteristics in relation to fruit coating in general. The palm oil at $0.3 \%$ in mixture with hydroxymethyl propyl cellulose $0.1 \%$ coating of guava fruit at $24^{\circ} \mathrm{C}$ and $65 \% \mathrm{RH}$ produced a quality stored fruits (for $12 \mathrm{~d}$ ) by cessation of peroxidase and polyphenol [17]. Moreover, coating of guava with a mixture of $4 \%$ glycerin, $2 \%$ calcium and $2 \%$ xanthan gum produced a significant effect in guava quality
[18]. Oil palm edible emulsion best application of guava postharvest treatment was found to be at $63^{\circ} \mathrm{C}$ and for 15 seconds dipping [19]. Coating of lemon fruits with pure coconut oil, liquid paraffin wax and castor oil preserve fruit quality for $18 \mathrm{~d}$ and prevent mould which occurred in the control fruits in day 12. This was due to stopping of the degradative metabolism (catabolism) which also include the chlorophyll pigments [20]. However, NO effected browning in guava which may be due to catabolic exhaust of some contents of the rind cells and its chlorophyll. This is corroborated by the findings in an earlier study that reported the appearance of brown spots in coated lemon fruits with sesame oil and mustard oil [20]. Essential oils from marjoram tree showed antimicrobial activity and preserved quality guava fruits for $28 \mathrm{~d}$ under room conditions. The corresponding control samples reflected deterioration in the quality indexes under the same storage conditions [21]. Five dibble oils were tested in coating guava fruits. These were namely, mustard oil (T1), coconut oil (T2), olive oil ( $\mathrm{T}_{3}$ ), almond oil ( $\left.\mathrm{T}_{4}\right)$ and grape seed oil ( $\left.\mathrm{T}_{5}\right)$. $\mathrm{T}_{3}$ gave the best results in extending the shelf life of guava fruits up to $28 \mathrm{~d}$ under cold storage and $16 \mathrm{~d}$ at ambient temperature in Punjab, India [22]. These results supported the findings of guava fruit treatment with olive oil in this study. However, recently a new modification in fruit edible coating emerged. The design of this new generation permit a meticulous release of antioxidants, vitamins, nutraceutics and antimicrobilas. These processes are facilitated by advanced nanoencapsulation and layer-by-layer assembly technologies [23]. Coating fruits with melted wax at high temperature is desirable and enables altering the permeability of their rind and preserve their moisture and consequently their market quality [24]. Nonetheless, coating is also used besides packing and surface additives to protect food commodities from chilling too [25]. However, the effect of clove oil (01\%), cinnamon oil (0.1\%) and cassava starch at 1 and $3 \%$ as coatings of guava fruits reflected results that rank the clove oil at $01 \%$ as the best in preservation of guava fruit quality at $8 \pm 1^{\circ} \mathrm{C}$ and 90\% RH [26]. All these citations displayed the importance of edible coating of oils and the advancements achieved in this field. These findings support our results in this study.

Table 1: Insect infestation in oil-coated guava fruits

\begin{tabular}{lllllllllll}
\hline Concentration & \multicolumn{9}{l}{ Disinfestation (\%) } & \multicolumn{2}{l}{ Worms/infested fruit } & & \multicolumn{2}{c}{ Infestation } \\
\cline { 2 - 10 } & Test & Control & Corrected & Test & Control & Difference & Diff. (\%) & Range & Mode & (\%) \\
\hline GNO & 96 & 16 & 80 & 4 & 10 & 6 & 150 & $0-4$ & 4 & 4 \\
SO & 88 & 16 & 72 & 17 & 10 & 7 & 41 & $2-25$ & 6 & 12 \\
BO & 72 & 16 & 56 & 11 & 10 & 1 & 9 & $2-26$ & 4 & 28 \\
OO & 68 & 16 & 52 & 5 & 10 & 5 & 100 & $1-13$ & 6 & 32 \\
NO & 40 & 12 & 28 & 7 & 26 & 19 & 271 & $1-17$ & 4 & 60 \\
Control 1 & & 16 & & & 10 & & & $3-23$ & 4 & 84 \\
Control 2 & & 12 & & & 26 & & & $2-109$ & 6 & 88 \\
\hline
\end{tabular}

Table 2: Fruit quality results of oil-coated guava fruits

\begin{tabular}{|c|c|c|c|c|c|c|c|c|}
\hline \multirow[t]{2}{*}{ Concentration } & \multicolumn{3}{|c|}{$\begin{array}{l}\text { Sustainability of Fruit Color } \\
\text { (FC) (\%) }\end{array}$} & \multicolumn{3}{|c|}{$\begin{array}{l}\text { Sustainability of Fruit Firmness } \\
\text { (FF) (\%) }\end{array}$} & \multicolumn{2}{|c|}{$\begin{array}{l}\text { Fruit Firmness Average } \\
\text { (FFA) }\end{array}$} \\
\hline & Test & Control & Corrected & Test & Control & Corrected & Treatment & Control \\
\hline GNO & 72 & 08 & 64 & 72 & 24 & 48 & 3 & 4 \\
\hline SO & 88 & 08 & 80 & 64 & 24 & 40 & 3 & 4 \\
\hline BO & 52 & 08 & 44 & 72 & 24 & 48 & 3 & 4 \\
\hline $\mathrm{OO}$ & 60 & 08 & $5^{2}$ & 96 & 24 & 72 & 3 & 4 \\
\hline NO & 16 & 20 & -4 & 72 & 24 & 48 & 3 & 4 \\
\hline Control 1 & 08 & & & 32 & & & 4 & 4 \\
\hline Control 2 & 20 & & & 28 & & & 4 & 4 \\
\hline
\end{tabular}


Table 3: Composition of the test oils

\begin{tabular}{|c|c|c|c|c|c|c|c|}
\hline \multirow[t]{2}{*}{$\begin{array}{l}\text { Oil } \\
\text { name }\end{array}$} & \multicolumn{2}{|c|}{ Saturated fatty acids (\%) } & \multicolumn{2}{|c|}{$\begin{array}{l}\text { Monounsaturated fatty acids } \\
\text { (\%) }\end{array}$} & \multicolumn{2}{|c|}{$\begin{array}{l}\text { Polyunsaturated fatty } \\
\text { acids (\%) }\end{array}$} & \multirow[t]{2}{*}{ Others } \\
\hline & $\begin{array}{l}\text { Palmitic } \\
\text { acid }\end{array}$ & $\begin{array}{l}\text { Stearic } \\
\text { acid }\end{array}$ & Oleic acid (o-9) & Others ( $\omega-7)$ & 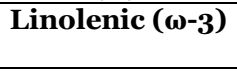 & $\begin{array}{l}\text { Linoleic } \\
(\omega-6)\end{array}$ & \\
\hline $\mathrm{BO}[27]$ & 27 & O3 & 30 & & 23 & 14 & Maluvic acid (3\%) \\
\hline GNO[27] & 17 & 02 & 48 & & Traces & 33 & \\
\hline $\mathrm{NO}[28]$ & $25(16-34)$ & $15(6-24)$ & $42(25-58)$ & & & $12(6-17)$ & \\
\hline $\mathrm{OO}[27]$ & 13 & 02 & 75 & & 01 & 09 & \\
\hline $\mathrm{SO}[29]$ & 08 & 05 & 39 & 0.7 & 0.7 & 41 & Traces of maluvic \\
\hline
\end{tabular}

Table 4: Mean absolute viscosities of test oils

\begin{tabular}{lll}
\hline Oil Name & Temperature $\left({ }^{\circ} \mathbf{C}\right)$ & Viscosity (Pa. S) (10 $\left.\mathbf{S}^{-4}\right)$ \\
\hline BO[30] & 30 & 418 \\
GNO[30] & 26 & $574 \pm 7$ \\
& 38 & $380 \pm 2$ \\
NO[31,32] & 54 & $236 \pm 3$ \\
& $30[3]$ & 835 \\
OO[30] & $40[2]$ & 455 \\
& 26 & $562 \pm 3$ \\
SO[30] & 38 & $341 \pm 5$ \\
& 50 & $261 \pm 3$ \\
& 26 & $525 \pm 7$ \\
& 38 & $351 \pm 2$ \\
\end{tabular}

\section{CONCLUSION}

Coating of guava fruit with edible GNO, SO, BO and OO reflected good quality of stored fruits at ambient temperature. This besides give a good control of the notorious pests of guava fruits, the fruit flies. However, in addition to the added nutritional value and its economies this practice it also considered safe to man and his environment.

\section{REFERENCES}

1. Paull RE and Bittenbender HC (2006). Guava (Psidium gayava L.), Mytraceae. In: Janick and Paull RE (2006). The Encyclopedia of fruits and nuts. Cambridge University Press, Cambridge. Pp. 541-49.

2. Morton J. (1987). Fruits of warm climate (1987). Published by Julia F. Morton, 20534 SW 92 Ct. Miami, FL. 33189. ISBN: 0-9610184-1-O, Distributed by Creative Resource Systems, Inc. Box 890, Winterville, N. C. 28590.

3. Paull RE and Duarte O (2010). Tropical fruits. $2^{\text {nd }}$ edition volume 1. MPG books group, UK. Pages 107, 108 and 120.

4. Ali SAI, Mohamed SA, Mahmoud, MEE, Sabiel, SAI, Ali S, and Ali A. (2014). Monitoring of tephritidae of fruit trees and their level of infestation in South Kordofan State, Sudan. IJAIR, 2: 687-693.

5. Gasmallah AE, Mekki MH, Abdelatief IA, Eljack AE and Ali OA. (2017). Screening of guava genotypes to natural infestation of fruit flies (Diptera: Tephritidae) in River Nile, Sennar and North Kordofan States, Sudan. International journal of environment agriculture and biotechnology, 2: 1130-1138.

6. Baldwin E (2007). Surface treatments and edible coating in food preservation. In: Rahm MS (2007). Handbook of food preservation. CRC, ISBN 9781574446067. Pp. 496 of 1088.
7. Dhall RK (2013). Advances in edible coatings for fresh fruits and vegetables: a review. Crit Rev Food Sci Nutr. 53:435-50.

8. Valencia-Chamorro SA, Palou L, Del Río MA, PrézGaqo MB (2011). Antimicrobial edible films and coatings for fresh minimally processed fruits and vegetables: a review. Crit Rev Sci Nutr., 51: 872-900.

9. Vishwasrao C and Ananthanarayan L. (2016). Postharvest shelf-life extension of pink guavas (Psidium guajava L.) using HPMC-based edible surface coatings. J Food Sci Technol. 3:1966-74.

10. Tomas SA, Bosquez-Molina E, Stolik S and Sánchez F (2005). Effect of mesquite gum-candelilla wax based edible coating on the quality of guava fruit (Psidium guajava L.). J. Phys. IV France, 125:889-892.

11. Mohamed S, Kyi K, Idris A, Yusof S and Osman A. (1992). Effect of various surface treatments (palm oil, liquid paraffin, samperfresh or starch surface coatings and LDPE wrappings) on the storage life of guava (Psidium guajava L.) at $10^{\circ} \mathrm{C}$. Acta Hortic. 321, 786794.

12. Kabbashi EBM and Nasr OE (2012). Effect of guava fruit colour and size on fruit fly incidence in Khartoum State. TJPP Vol. 7, No. 2. Pp 79.

13. Kabbashi EBM. Investigation and criticism into Abbott's formula. Sudan Journal of Scientific Research, 2005;8 : 102-111.

14. Liu X, Jin Q, Huang J, Wang X, Mao W and Wang S (2011). Change in volatile compounds of peanut oil during the roasting process for population of aromatic roasted peanut oil. Journal of food science, 76: C404-12.

15. Dass PM Danbature WL, Karu E, Ibrahim A and Ledo $\mathrm{AB}$ (2013). Extraction and biodegradation of baobab (Adansonia digitata L.) seed oil by fungi (Aspergillus spp.). Journal of natural science research, 3: 128136. 
16. Ambrose-Oji BO and Mughogho B (2007). Adansonia Za Baill (2007). In: van der Vossen HAM. Porta 14:Vegetable oils/oléagineux. Pprta, Wageningen, Netherlands.

17. Vishwasrao C and Ananthanarayan L. (2017). Delayed postharvest associated changes in Manilkara zapota L. Var. Kalipatti with composite edible coating. J. Sci Food Agric., 97: 536-542.

18. Bilawal A., Hashim MS, Zareen S, Amir NN and Khan I (2017). Effect of edible gum coating, glycerin and calcium lactate application on the postharvest quality of guava fruit. International journal of advanced research and publication, 1: 23-27.

22. Zahid AM, Cheow CS, Norizzah AR, Zahran HMS, Adi MS, Noorakmar AW and Ruzaina I (2011). Optimization of process conditions for the application of edible coating emulsion on guava (Psidium guajava L.) using response surface methodology. A Proceeding of the $2^{\text {nd }}$ international conference on biotechnology and science, 2011. Pp, 61-65.

23. Bisen A, Pandey SK and Neha Patel N (2012). Effect of skin coating on prolonging shelf life of kagzi lime fruits (Citrus aurantifolia Swingle). $J$ Food $\mathrm{Sci}$ Technol. 49: 753-759.

24. Othman ME, El-Badry N, Mahmoud S and Amer M (2017). Effect of edible coating contained essential oil on the quality attributes and prolonging the shelf life of guava fruit. Middle East journal of agriculture, 6: 161-74.

25. Singh H, Kachway DS, Kuschi VS, Vikas G, Kaushal N and Sigh A (2017). Edible oil coatings prolong shelf life and improve quality of guava (Psidium guajava L.). Int. J. Pure app, biosci. 5: 837-843.

26. Vargas M, Pastor C, Chiralt A, Mc Clements DJ, González-Martínez C. (2008). Recent advances in edible coatings for fresh and minimally processed fruits. Crit Rev Food Sci Nutr. 48:496-511.

27. Singh NK, Evranuz EÖ, Siddig M, Ahmed G and Hui YH (2011). Handbook of vegetables and vegetable processing. Wiley-Blackwell, a John Wiley and Sons, Ltd, Publication, Aimes, Iowa, USA.

28. Fallik E, Temkin GN, Grinberg $\mathrm{S}$ and Davidson $\mathrm{H}$ (1994). Vacuum cooling wrapped lettuce. California Agric. 33:18-19.

29. Shaaban FKM and Hussein AMS (2017). Influence of some safety postharvest treatments on fruit quality and storability of guava fruits. Current science international, 6: 491-500.

30. Anonymous (2016). US national nutrient database 28 . USDA, May 2016.

31. Kaushik N and Vir S (2000). Variation in fatty acid composition of neem seed collected from the Rajasthan State of India. Biochemistry Soc Trans, 28. 880-2.

32. Anonymous (2014). Nutrition facts from sesame oil per $100 \mathrm{~g}$, analysis of fatty acids. Conde Nast for the USDA National Nutrient Database, SR-21, 2014.

33. Diamante LM and Lan T (2014). Absolute viscosities of vegetable oils at different temperatures and shear rate range of 64.5 to $4835 \mathrm{~S}^{-1}$. Journal of food processing, volume 2014, article ID 234583, 6 pages.

34. Bhandare $P$ and Naik GR (2015). Functional properties of neem oil as a potential feedstock for biodiesel production. International letters of natural science, 7:7-14.

35. Sucharitha G and Kumaraswamy A (2013). Experimental analysis of using neem oil as an alternative fuel. International journal of engineering research and application (IJERA), 3: 320-325. 